\title{
O PAPEL DO JUIZ CRIMINAL NO ESTADO DEMOCRÁTICO DE DIREITO
}

\author{
Dani Rudnicki* \\ Bruna Vidal da Rocha \\ Letícia Sinatora das Neves ${ }^{* *}$
}

RESUMO: O presente trabalho busca realizar aproximações entre o Estado Democrático de Direito e o ato de julgar do juiz criminal nesse Estado. Pretende-se demonstrar qual o efetivo papel do julgador dentro das regras do processo penal, alertando para os limites e eventuais riscos à democracia. Para tanto, utilizou-se como metodologia a revisão bibliográfica e doutrinaria, que se compreende como meio de se conhecer o funcionamento do sistema e organizar o pensamento sobre as formas de perceber o papel do juiz no processo e melhor garantir a efetividade da democracia no país.

Palavras-chave: Democracia; Processo Penal; Estado; Limites; Julgador.

\section{THE CRIMINAL JUDGE'S ROLE IN THE DEMOCRATIC STATE OF LAW}

ABSTRACT: The presente paper aims to analize approximations between the Democratic State of Law and the act of judging of criminal judge in that State. It's intended to demonstrate the effective judge's role within the rules of criminal procedure, alerting to the limits and possible risks to democracy. For this purpose, the bibliographic and doctrinal review was used as a methodology, which is understood as a means of knowing the functioning of the system and organizing the thinking on ways to perceive the role of the judge in the process and better guarantee the effectiveness of democracy in the country.

Keywords: Democracy; Criminal procedure; State; Limits; Judge

\section{Introdução (e algumas aproximações com o Estado Democrático de Direito)}

Este artigo pretende, a partir dessas concepções acerca do Estado Democrático de Direito, analisar qual o papel do Juiz Criminal dentro do devido processo penal. Para tanto, considera-se importante a compreensão do que seja Estado Democrático de Direito. Luigi

\footnotetext{
* Doutor em Sociologia pela UFRGS. Mestre em Direito pela Unisinos. Professor do Programa de PósGraduação em Direito na Universidade LaSalle. Advogado.

${ }^{* *}$ Mestra em Direitos Humanos (Uniritter, bolsista CAPES integral); Especialista em Direito Penal e Processual Penal (Uniritter); Professora da Graduação da Universidade Dom Alberto. Advogada. E-mail: brunavidal.r@hotmail.com

${ }^{* * *}$ Mestre em Direito Fundamentais (ULBRA), Especialista em Ciências Penais (PUC/RS); Professora da Graduação em Direito Uniritter e de Cursos preparatórios para Exame Nacional da Ordem dos Advogados do Brasil; Advogada. E-mail: leticia_neves@msn.com
} 
Ferrajoli descreve o Estado de direito como sinônimo de garantismo, uma vez que designa não apenas um Estado legal ou regulado por lei, mas sim um modelo de Estado nascido com as Constituições e caracterizado pelo princípio da legalidade, pelo qual todo poder está subordinado às leis gerais e abstratas e pela aplicabilidade de todos os poderes do Estado a serviço da garantia dos direitos fundamentais dos cidadãos. Em outras palavras, o Estado deve garantir que não sejam lesionados os direitos de liberdade e deve efetivar os direitos sociais inerentes a cada um. (FERRAJOLI, 1997, p.p. 856/857)

Ressalte-se que a República Federativa do Brasil se constitui em Estado Democrático de Direito e tem como fundamentos a soberania, cidadania, dignidade da pessoa humana, os valores sociais do trabalho e da livre iniciativa e o pluralismo político. Tal Estado se traduz no respeito às garantias e direitos fundamentais por parte das autoridades públicas, bem como à imposição de subordinar-se às normas democráticas, com eleições livres, periódicas e pelo povo. (MENDES; COELHO; BRANCO, 2009, p. 70).

Em observância a esses ditames, o Estado Democrático de Direito se funda na ideia de justiça social e, para que se identifique como democrático, deverá declarar e assegurar os direitos fundamentais que se apresentem vinculantes para a produção e interpretação do ordenamento jurídico nacional, bem como para o exercício do poder estatal. (TOLEDO, 2003, p.p 112/116)

Dentro desse contexto, o processo penal deve ser compreendido como instrumento de efetividade de um Estado Democrático de Direito. Essa instrumentalidade é o fundamento da sua existência e surge principalmente para resguardar direitos e garantias individuais da parte mais vulnerável dentro do processo - o réu. Assim, o processo penal, apesar da sua relação com o Direito Penal, não pode se descuidar dos objetivos traçados, entre os quais está a proteção do indivíduo, reforçando o projeto constitucional. (LOPES JR. 2020, p. 62)

A razão de ser do processo penal não está apenas na persecução criminal do indivíduo e na sua condenação, mas também na função de garantir o devido processo penal, conferindo a quem se vê acusado de um crime suas garantias fundamentais e um processo justo.

O devido processo penal, portanto, é aquele que formal e materialmente protege os direitos humanos e direitos fundamentais, principalmente a liberdade do cidadão. A adoção ao devido processo com a aplicação das regras a ele pertinentes, sejam elas convencionais, constitucionais, legais e/ou garantidoras dos direitos humanos e fundamentais não significa 
impunidade, mas sim aperfeiçoamento do Estado Democrático de Direito. (GIACOMOLLI, 2016, p. 99)

A fim de alcançar esses objetivos, utiliza-se como metodologia a revisão bibliográfica e doutrinaria. Esse é meio de se conhecer o funcionamento do sistema e organizar o pensamento sobre as formas de perceber o papel do juiz no processo e melhor garantir a efetividade da democracia no país.

\section{0 “julgar” do Juiz Criminal no Estado Democrático de Direito}

No Estado Democrático de Direito vigem os direitos garantidos desde o século XVIII, quando a Revolução Francesa iniciou o processo de modernização das instituições, garantindo aos cidadãos não apenas a liberdade e igualdade, mas também a legalidade e a presunção de inocência, bases do direito penal de garantias.

Nesse novo Estado, no qual se garante ao indivíduo a liberdade a fruição de direitos, os agentes públicos assumem novas posições. Eles deixam de ser empregados do Rei absolutista e passam a ser a "boca da lei" ("bouche de la loi"); lei determinada por um poder Legislativo autônomo. Com o passar do tempo, adquirem os juízes maior poder e liberdade no julgar. Esta função, entretanto, necessita estar limitada pelo Poder Constitucional.

Para Amilton Bueno de Carvalho (CARVALHO, 1997, p. 368), o Juiz da Democracia “[...] não deve julgar ou julgar o mínimo possível”. Ele faz essa afirmação sob a perspectiva de que o processo surge quando as pessoas não possuem mais a capacidade de dialogar, quando perdem a autonomia de resolver seus próprios conflitos, necessitando o Estado-juiz para resolver o conflito.

No Estado Democrático de Direito, o juiz assume uma nova posição, sendo que o que legitima a sua atuação não é a questão política, mas sim a constitucional, consubstanciada na função de proteção dos direitos fundamentais dos indivíduos, ainda que para isso ele tenha que adotar posição contrária ao entendimento majoritário. (LOPES JR. 2020, p. 59).

Assim, apenas saber a legislação e a jurisprudência não é o suficiente, uma vez que aplicar a letra fria da lei poderia, por vezes, acarretar injustiças. As faculdades de direito, ao tratarem a lei como dispositivos inquestionáveis, perdem o senso crítico, fazendo crer que se deve conhecê-la, mas nunca a questionar. (LOPES JR. 2020, p. 59) Portanto, caberia ao 
julgador a tarefa de, além de conhecer a lei, interpretá-la e decidir a respeito da sua (não)aplicação. Nessa linha, esquece-se que tanto o julgador, quanto o acusado são, antes de tudo, seres humanos e a aplicação da letra fria da lei sem uma análise mais precisa do acontecimento poderia gerar uma desproporção em eventual medida punitiva.

Na mesma linha, Luigi Ferrajoli afirma: "la sujeción del juez a la ley ya no es, como en el viejo paradigma positivista, sujeción a la letra de la ley, cualquiera que fuere su significado, sino sujeción a la ley em cuanto válida, es decir, coherente con la Constitución, coherencia más o menos opinable y siempre remitida a la valoración del juez." (FERRAJOLI, 2001, p. 26). ${ }^{1}$ Sendo assim, é no momento da análise do caso e ao julgar que o juiz possui certa liberdade na interpretação das normas jurídicas, não se submetendo, exclusivamente, à letra fria da lei, ficando adstrito ao conteúdo da Constituição.

Da mesma forma, o papel do juiz pode, também, ser visualizado como um papel de redução de danos. Seu condenar nada mais é do que a afirmação de que o Estado falhou em determinado momento, não logrou êxito em solucionar conflitos de forma civilizada e, a eles (os juízes), lhes resta o "[...] triste papel de ser a ponta da lança do poder: legitimar o sofrimento estéril, dando a falta e infantil sensação de que 'agora, com a prisão do indesejado, estamos em segurança." (CARVALHO, 2014. p. 45) Ou seja, aos juízes cabe a tarefa de confirmar a falha do Estado em proteger o cidadão e de evitar que os crimes ocorram. É a mais dura e verdadeira prova de que o Estado falhou desde o princípio, seja com o acusado, seja com a vítima.

Relembra-se, ainda, que o ato decisório do juiz é denominado de sentença que deriva de 'sentir', atribuindo-lhe uma tarefa totalmente subjetiva, o julgar com base no sentimento, buscando argumentos técnicos que lhe permitam esconder tal subjetividade e persuadir o órgão crítico (CARVALHO, 1987, p. 140). O juiz, por mais que tente ser imparcial, não deixa de ser um ser humano, que tem experiências de vida e que, ao julgar, mesmo que não queira, está carregando todas suas experiências para dentro da sentença, para dentro do seu "sentir", como diria Amilton Bueno de Carvalho. A solução para o julgar penal seria, então, o dever do julgador de ter empatia com o acusado, de colocar-se no lugar do outro, na pele do outro e, junto com ele, sentir suas dores e dar a resposta penal menos dolorida possível. (CARVALHO, 2014, p. 53)

\footnotetext{
1 “A sujeição do juiz à lei já não é mais, como no velho paradigma positivista, sujeição à letra fria da lei, qualquer que fosse seu significado, senão sujeição à lei enquanto válida, é dizer, coerente com a Constituição, coerência mais ou menos opinável e sempre remetida à valoração do juiz”. Tradução nossa.
} 
A posição de Amilton Bueno de Carvalho se aproxima da ideia de Francisco Carnelutti, em sua obra "As misérias do processo penal", de que o encarcerado é um necessitado (de amizade), pois ele sente que as pessoas estão contra ele. Dessa forma, faz-se necessário colocar-se em seu lugar para compreender sua solidão e necessidade de companhia. Logo, quando pensa sobre a essência do papel do advogado de defesa, Carnelutti escreve sobre sentar-se ao lado do acusado, dividir com ele a necessidade de ser julgado. $\mathrm{O}$ atuar no processo penal exige com que nos coloquemos no lugar do outro não apenas como advogados de defesa, mas também como acusadores e julgadores, compreendendo a situação em que se encontra o acusado.

Interessante a posição adotada por Amilton Bueno de Carvalho no Livro "Eles, os juízes criminais, vistos por nós, os juízes criminais" ao sustentar a relação do advogado de defesa com o acusado. O acusado, na maioria das vezes, sente que muitas pessoas estão contra ele. Dessa forma, faz-se necessário colocar-se no lugar destes acusados para que seja possível compreender a sua solidão e, com isso, a necessidade de companhia. A essência do papel do advogado de defesa é sentar-se ao lado do acusado, dividir com ele a necessidade de pedir e de ser julgado, ou seja, o atuar no processo penal exige com que nos coloquemos no lugar do outro não apenas como advogados de defesa, mas também como acusadores e julgadores, compreendendo a situação em que se encontra o acusado. (CARNELUTTI, 2004. p.p. 27/31)

José Francisco Fischinger Moura de Souza assevera que “[...] o juiz criminal previsto na lei é em grande parte incompatível com o juiz criminal constitucional" e o faz sob os argumentos de que o magistrado que atue sobre a lei, sem dar enfoque à Constituição é autoritário e pode ser considerado parcial. Conduz o processo sem o respeito aos prazos, possui contato com os atos investigatórios, pode agir como instrutor, o que é o caso do artigo 156 do Código de Processo Penal, e pode agir como juiz responsável pelo juízo de acusação (SOUZA, 2004, p.p. 315/316)

Na ritualística processual penal, o artigo 156, caput, do Código de Processo Penal, determina que a prova da alegação caberá a quem a fizer, entretanto, abre exceção nos incisos seguintes. O inciso I permite que o juiz ordene, mesmo antes do início da ação penal, a produção antecipada de provas consideradas urgentes e relevantes, observando a necessidade, adequação e proporcionalidade da medida. Isso nada mais é do que permitir que o juiz saia da posição de expectador e passe a um papel ativo ainda na fase de investigação. 
Neste ponto, importante ressaltar um aspecto extremamente criticado no Processo Penal brasileiro que é a determinação da competência pelo critério da prevenção prevista no artigo 83, in verbis:

\begin{abstract}
Verificar-se-á a competência por prevenção toda vez que, concorrendo dois ou mais juízes igualmente competentes ou com jurisdição cumulativa, um deles tiver antecedido aos outros na prática de algum ato do processo ou de medida a este relativa, ainda que anterior ao oferecimento da denúncia ou da queixa (arts. 70, § 3o, $71,72, \S 20$, e 78, II, c) Ou seja, o juiz que determinar, por exemplo, a realização de escuta telefônica, será o mesmo juiz que sentenciará o acusado e, nesse sentido, como esperar imparcialidade do julgador quando ele está contaminado com a decisão da produção de provas ainda na fase investigatória? A fixação da competência por regra de prevenção é, em realidade, altamente prejudicial ao princípio básico que deve nortear o processo penal democrático: a imparcialidade do juiz. (LOPES JR. 2017, p.p . 65/66)
\end{abstract}

Já o inciso II do mesmo dispositivo legal permite que, de ofício, no curso da instrução ou antes de proferir sentença, o juiz determine a realização de diligências para dirimir dúvida sobre ponto relevante. Ressalta-se que um dos princípios basilares do processo penal é o princípio do in dubio pro reo, que significa que diante de dúvida, deve-se decidir a favor do réu. Logo, permitir que o juiz determine a diligência em busca de provas para dirimir eventuais dúvidas é, mais uma vez, autorizar que o julgador abandone o seu papel de expectador e assuma um papel ativo dentro do processo penal e, sendo assim, não há como esperar uma imparcialidade do julgador quando ele mesmo age no sentido de produzir provas.

Esse dispositivo tem amparo no mito ilusório da busca pela "verdade real" em contraposição à verdade processual, demonstrando características de um sistema inquisitório, contrário ao que dispõe a Constituição Federal ao definir o sistema processual penal como acusatório. (CHOUKR, 2009, p.p. 312/317). A busca pela "verdade real”, portanto, se torna responsável por abusos e violações de direitos individuais. Vale ressaltar que a legislação processual penal é de 1941 e, inegavelmente, possui inspirações autoritárias. Muito embora o referido artigo tenha sofrido alterações pela Lei 11.690/08, não foi retirada do juiz a possibilidade de produzir provas, colocando em xeque todo o ideal de um devido processo penal, ao permitir que o juiz saia de uma posição de espectador e assuma uma posição ativa de acusador.

Nesse contexto, convém referir que a Lei 13.964/19, conhecida como Pacote Anticrime, introduziu no Código de Processo Penal o artigo $3^{\circ}$-A, que consagra na legislação infraconstitucional a estrutura acusatória e veda expressamente a iniciativa probatória do juiz, 
corroborando com a Constituição Federal. Entretanto, tal dispositivo está com a eficácia suspensa em virtude da concessão de liminar nas Ações Diretas de Inconstitucionalidades n. 6.298, 6.299, 6.300 e 6.305, concedidas pelo Ministro Fux. A vigência do dispositivo em questão imporá uma série de consequências à atuação dos magistrados de forma expressa, impedindo a posição ativa de acusador de forma radical.

Essa posição ativa de acusador, em um Estado Democrático de Direito - no qual o juiz tem o dever de ser um garantidor dos direitos fundamentais, de limitar o poder estatal a fim de prevenir qualquer tipo de arbitrariedade - acaba reforçando a acusação quando permite a gestão de provas por parte do julgador, na medida em que a simples dúvida seria suficiente para um juízo absolutório e a busca pela produção de provas seria, portanto, responsabilidade da acusação e não do juiz. O envolvimento do juiz na gestão probatória fere gravemente o princípio da imparcialidade, essencial para a função jurisdicional.

A imparcialidade determina ao julgador um afastamento estrutural em relação às atividades das partes. Dessa forma, é necessário diferenciá-la da ideia de neutralidade. Ser imparcial não significa ser neutro. A neutralidade, por sua vez, não existiria pelo fato de que ainda que o julgador procure ser imparcial, seu julgar reflete um sentimento, uma eleição por um dos lados apresentados que são o conjunto de fatores psicológicos e experiências de vida que envolvem e afetam o ato de julgar. Não se pode esquecer que o julgador também é um ser humano e, como tal, possui experiências próprias de vida, o que impede que ele seja absolutamente neutro, mas não impede que seja imparcial (e assim deve ser) (LOPES JR. 2020, p. 877).

O conceito de imparcialidade é diferente do conceito de neutralidade que, por pretender uma utópica abstração subjetiva, um completo isolamento do ser humano em relação ao contexto social em que está inserido, demonstra-se inalcançável ao sujeito e, portanto, ao julgador (MAYA, 2014, p. 48).

A exigência da imparcialidade do Juiz Criminal está expressamente assegurada como garantia judicial no artigo $8^{\circ}, \mathrm{n}^{\circ} 1$, da Convenção Americana de Direitos Humanos, in verbis:

Artigo $8^{\circ}$ - Garantias judiciais 1 . Toda pessoa terá o direito de ser ouvida, com as devidas garantias e dentro de um prazo razoável, por um juiz ou Tribunal competente, independente e imparcial, estabelecido anteriormente por lei, na apuração de qualquer acusação penal formulada contra ela, ou na determinação de seus direitos e obrigações de caráter civil, trabalhista, fiscal ou de qualquer outra natureza. (BRASIL, 1992) 
Inclusive, tem sido debatida nas decisões do Tribunal Europeu de Direitos Humanos, desde 1982, quando, no Caso Piersack vs. Bélgica, o TEDH considerou violado o direito a um juiz imparcial em função de que o julgador que presidiu o Tribunal e condenou Piersack ter sido o mesmo que coordenou a promotoria que investigou o caso. Ainda que indiretamente, no presente caso houve a superposição das funções de acusar e julgar, violando a regra de imparcialidade do julgador, na medida em que há dúvida acerca da imparcialidade e a dúvida já seria o suficiente para essa violação (GIACOMOLLI, 2016, p. 288).

Aceitar e legitimar a produção de provas pelo julgador retira a imparcialidade necessária para um julgamento justo. O julgador que requer a produção de provas para dirimir dúvidas está em busca de uma condenação, pois se seu desejo fosse o de absolver, a simples dúvida seria suficiente já que ele estaria amparado pelo princípio do in dubio pro reo e pela previsão constitucional da presunção de inocência. Ou seja, o julgador que sai do seu papel de mero expectador e busca uma prova possui um juízo de convicção e está nada mais do que buscando prova que justifique sua sentença.

Diante de todo o exposto, o papel do juiz no processo criminal é o de conduzir o processo e garantir um julgamento justo e imparcial com o devido respeito a todas as garantias constitucionais e direitos fundamentais, principalmente a garantia de presunção de inocência prevista no artigo $5^{\circ}$ da Constituição Federal. Carlos Maria Cárcova acrescenta que:

\footnotetext{
Segundo parece: conhecem, interpretam, valoram, deslindam, estipulam, não de uma maneira monádica, ilhados, solitários e caprichosos. Senão, como seres sociais, portadores de uma cultura técnica, mas irredutivelmente permeáveis ao conjunto de representações, estados de consciência e visões do mundo que compartem com seus congêneres e auxiliam, com seu trabalho, às vezes a conservar e outras a transformar Tradução nossa. (CÁRCOVA, 2001, p. 17)
}

O papel do juiz no Estado Democrático de Direito está em buscar a melhor solução ao caso concreto, de acordo com as provas e fatos que lhe são apresentados, de maneira imparcial. O julgador deve manter-se equidistante do conflito existente entre as partes, mas ainda assim deve julgar como ser humano que é. Para tanto, ele está munido de técnica aliada à experiência, para ao final, atingir o fim de reduzir os danos e dar a resposta mais adequada ao caso, assegurando ao máximo o respeito às garantias constitucionais.

\section{A relação entre os sujeitos processuais: limites e eventuais riscos à Democracia}


O panorama processual penal brasileiro pressupõe, como mencionado, a existência de um Juiz Criminal imparcial para atender a expectativa do projeto democrático, o que não significa que o magistrado venha ocupar um posto inalcançável, em um local isolado, afastado de todos. Ao contrário, do Juiz Criminal, em uma Democracia, se espera o comprometimento e a sensibilidade necessários à condução de um processo que se desenvolva com a observância das garantias e direitos de forma substancial, portanto estar disponível às partes é intrínseco às regras do jogo. (FERRAJOLI,1997, p. 38) explica que:

[...] El juez no es uma máquina automática en la que por arriba se insertan los hechos y por abajo se sacan las sentencias, acaso com la ayuda de algún empujón cuando los hechos no se adaptan perfectamente a ella. La idea de um perfecto silogismo judicial que permita la verificación absoluta de los hechos legalmente punibles corresponde, como veremos desde este capítulo, a una ilusión metafísica: em efecto, tanto las condiciones de uso del término 'verdadero' como los criterios de aceptación de la 'verdad' en el proceso exigen inevitablemente decisiones dotadas de márgenes más o menos amplios de discrecionalidad [...]

Assim, cabe ao juiz trabalhar para preencher as lacunas existentes e, a partir dessa noção, identifica-se na legislação ordinária que é dever do magistrado, assegurado na Lei Orgânica da Magistratura, atender aqueles que o procurarem; da mesma forma, é assegurado aos integrantes do Ministério Público e aos advogados se dirigirem aos magistrados nas salas e em seus gabinetes de trabalho:

É assegurado como dever do magistrado no artigo 35, inciso IV, da Lei Orgânica da Magistratura, Lei n. 35/1979, entre outras imposições: "tratar com urbanidade as partes, os membros do Ministério Público, os advogados, as testemunhas, os funcionários e auxiliares da Justiça, e atender aos que o procurarem, a qualquer momento, quanto se trate de providência que reclame e possibilite solução de urgência”. Da mesma forma, a Lei 8.906/1994, Estatuto da Advocacia, também assegura ao advogado no exercício profissional o direito de se dirigir diretamente aos magistrados nas suas salas e gabinetes de trabalho (artigo 7, VIII). Inclusive, a Lei Orgânica Nacional do Ministério Público, Lei n. 8.625/1993, no artigo 41, inciso VI, preconiza como prerrogativa dos membros do Ministério Público: "ingressar e transitar livremente nas salas de sessões de Tribunais, mesmo além dos limites que separam a parte reservada aos Magistrados (BRASIL, 1979).

Não há, portanto, qualquer ilegalidade em relação ao contato pessoal do Juiz Criminal com as partes do processo, aliás é imprescindível ao devido processo legal que seja franqueado esse acesso ao magistrado. Entretanto, em prol de uma convivência democrática 
no âmbito do processo penal, a expectativa é de que essa comunicação entre os sujeitos processuais aconteça em locais públicos e se realize como forma de manifestação da prestação jurisdicional, respeitando, por consequência lógica, a paridade de armas ente a acusação e defesa.

A problemática central reside justamente na tarefa de identificar os limites aceitáveis impostos à relação entre esses sujeitos. No entanto, não se trata de fácil tarefa, considerando a visível ideologia autoritária presente no processo penal brasileiro, que o concebe exclusivamente como um instrumento necessário à aplicação da pena, seguindo-se da ideia de que os direitos e garantias fundamentais seriam entraves à "eficiência do instrumento penalizador." (GLOECKNER , 2018, p. 77)

Nesse contexto, evidencia-se que a limitação da relação entre os sujeitos processuais demanda, principalmente, um esforço pessoal do Juiz Criminal em reconhecer a sua própria função de "garantidor da eficácia do sistema de direitos e garantias fundamentais do acusado no processo penal" (LOPES JR. 2020, p. 62) e, especialmente, blindar-se das "armadilhas que a estrutura inquisitória lhe impõe",2, buscando preservar a sua postura de imparcialidade imposta, sob a ótica de um processo penal democrático.

Para André Machado Maya, a imparcialidade é um valor estruturante da função jurisdicional, limitador dos poderes atribuídos aos magistrados, um padrão de referência que orienta a conduta profissional dos julgadores. Caracteriza-se como um instrumento de garantia do devido processo legal, apresentando-se como uma condição de legitimidade da atividade jurisdicional (MAYA, 2014, p. 101). Logo, é impossível vislumbrar um processo penal avesso à imparcialidade.

No intuito de garantir essa imparcialidade, ao menos formalmente, resta assegurada às partes do processo a possibilidade de impugnar o Juiz Criminal através das exceções de suspeição ou impedimento, conforme o disposto no artigo 95 do Código de Processo Penal. As hipóteses que caracterizam o impedimento ou suspeição do juiz estão nos artigos 252 a 254 do mesmo diploma legal.

Em que pese as limitações legais existentes, a questão da imparcialidade do Juiz Criminal é temática constantemente debatida; e não deveria. Não são poucos os casos em que se discute a postura dos magistrados na condução de processos penais ao extrapolarem, sob

\footnotetext{
${ }^{2}$ COUTINHO, Jacinto Nelson de Miranda. O papel do novo juiz no processo penal. Disponível em: Acesso em: 09/08/19.
} 
diversos ângulos, a sua função jurisdicional. Nos últimos anos, a problemática acerca da atuação do Juiz Criminal no Brasil foi destaque por diversas vezes nos veículos de comunicação nacionais e internacionais. Por diversas vezes, o ex-Ministro da Justiça e Segurança, Sérgio Fernando Moro, que ocupava a função de Juiz Federal na Vara Criminal, na qual tramitavam os processos referentes à Operação Lava Jato ${ }^{3}$, foi o cerne das discussões e teve a sua atuação questionada:

Em 2013, foi julgado pelo Supremo Tribunal Federal o HC n. 95.518, pertinente a Operação Lava Jato, no qual, entre outras questões, tinha como objeto o reconhecimento da atuação parcial por parte do Juiz Sérgio Fernando Moro, a evidenciar suspeição ou impedimento ao conduzir determinado processo penal. $\mathrm{Na}$ ocasião, o julgamento foi no sentido de denegar a ordem. Entretanto, diante de toda a discussão jurídica vivenciada, o Ministro Celso de Mello concedia a ordem de Habeas Corpus, sustentando que: "Na realidade, a situação exposta nos autos compromete, segundo penso, o direito de qualquer acusado ao "fair trial", vale dizer, a um julgamento justo efetuado perante órgão do Poder Judiciário que observe , em sua conduta, relação de equidistância em face dos sujeitos processuais, pois a ideia de imparcialidade compõe a noção mesma inerente à garantia constitucional do "due process

law”.(http://redir.stf.jus.br/paginadorpub/paginador.jsp?docTP=TP\&docID=546389 $2-$ p. 32).

A situação em questão assumiu uma dimensão diferenciada após a divulgação, no dia nove de maio de 2019, no site The Intercept Brasil ${ }^{4}$, de diálogos provenientes de mensagens, áudios e outros documentos trocados via aplicativo Telegram, entre o Juiz Criminal Sérgio Fernando Moro e Deltan Dallagnol, chefe dos procuradores que atuavam na Operação Lava Jato. O acesso a tais informações aconteceu, por óbvio, sem qualquer autorização dos envolvidos, sendo questionada a licitude da utilização dessas medidas, o que não impede que se atribua extrema relevância ao debate. Inobstante a origem e a forma de obtenção dessas informações, o que vem à tona é a inadequada relação existente entre juiz e acusação que, em caso de confirmação da veracidade do conteúdo, resultaria no impositivo reconhecimento da parcialidade do julgador, podendo acarretar nulidade a eventuais processos.

Devido a todo esse vazamento, no dia sete de novembro de 2019, levando em consideração toda a imparcialidade que se exige do julgador e os extensos pedidos de

\footnotetext{
${ }^{3}$ A Operação Lava Jato, iniciada em 2014, é intitulada como a maior operação no cenário brasileiro de combate à corrupção. (http://www.pf.gov.br/imprensa/lava-jato).

${ }^{4}$ GREENWALD, Glenn.; REED, Betsy; DEMORI, Leandro. COMO E POR QUE O INTERCEPT ESTÁ PUBLICANDO CHATS PRIVADOS SOBRE A LAVA JATO E SERGIO MORO. Disponível em: https://theintercept.com/2019/06/09/editorial-chats-telegram-lava-jato-moro/ Acesso em 09/08/19.
} 
realização de provas pelo juiz Sérgio Moro, que buscava incansavelmente a confirmação de José Inácio Lula da Silva, foi que o Supremo Tribunal Federal decidiu soltar o ex-presidente. (Denote-se aqui, a ausência de condão político na argumentação, mas apenas a necessidade de expor os fatos como se deram).

Por certo, diversas instituições e categorias se manifestaram em repúdio aos episódios, justificando as suas posições em defesa da Democracia ${ }^{5}$, pois, ainda que se utilize desses episódios como ilustração, é inaceitável em uma relação que deverá primar pela paridade de armas vislumbrar que a acusação e o juiz estejam unidos, pensando em estratégias de jogo. $\mathrm{O}$ juiz não é jogador, sim julgador. "Não se pode confundir o papel do julgador com o dos jogadores. As decisões do julgador estão vinculadas às jogadas.” (ROSA, 2013, p. 86).

Nesse contexto, o que se reclama é a necessidade de se (re)pensar o papel dos sujeitos processuais, especialmente o do Juiz Criminal, pois o risco à Democracia se verifica quando a máxima "os fins justificam os meios" é invocada em detrimento às garantias necessárias a um devido processo legal, quando se naturalizam práticas e ideologias autoritárias, e, no âmbito do processo penal, não se respeitam as regras da condução processual com lealdade ao projeto democrático.

De nada adianta um juiz que abandona seu papel de julgador e expectador e passa a assumir um papel de jogador do processo penal quando dele, juiz, se espera que decida com base nas provas que lhe são apresentadas, a fim de ratificar a existência de um efetivo Estado Democrático de Direito.

\section{Considerações Finais}

O presente artigo analisou o papel do Juiz Criminal no Estado Democrático de Direito. Foram abordadas questões conceituais acerca do Estado, aproximando-o com a teoria do garantismo, proposta por Luigi Ferrajoli quando atribui o seu surgimento às Constituições e o caracteriza pelo princípio da legalidade.

Em seguida, foram discutidas questões a respeito do processo penal, destacando-se justamente a sua instrumentalidade sob o viés garantidor, que surge para frear o poder

\footnotetext{
${ }^{5}$ ADVOGADOS. Carta Aberta. Disponível em: <https://www.conjur.com.br/dl/advogados-afastamento-moroministerio.pdf > Acesso em: 08/08/19
} 
punitivo do Estado e não apenas para garantir a aplicação de uma pena, mas também (e principalmente) para que sejam respeitados os direitos e garantias fundamentais dos sujeitos acusados criminalmente.

Com isso, concluiu-se que, ao juiz, cabe o dever de julgar de acordo com o que lhe é apresentado, mantendo-se distante do conflito. A produção probatória permitida ao julgador, faculdade ainda prevista no Código Processual, acabaria por retomar um traço do sistema processual inquisitório e retirar a sua imparcialidade, que é um valor estruturante para a devida prestação jurisdicional.

Em contrapartida, sustentar a imparcialidade e reforçar o seu valor na estrutura dialética do processo não significa atribuir ao juiz uma posição inalcançável, mas sim alertar para o fato de que, é intrínseco à relação processual em uma Democracia, o magistrado estar disponível às partes e atendê-las sempre que necessário. Entretanto, devem ser observados alguns limites que, se ultrapassados, poderão acarretar máculas insanáveis em processos criminais.

No Brasil, o episódio em que foram reveladas publicamente no site "The Intercept", em junho de 2019, mensagens entre a acusação e o juiz da Operação Lava Jato, Sérgio Fernando Moro, depois Ministro da Justiça e Segurança, com conteúdo voltado diretamente à persecução criminal, reforça que é imperioso que se observem sempre os limites na prestação jurisdicional e que o desprezo às regras inerentes põe em risco a própria estrutura democrática do processo. Ademais, posteriormente, em 2019, demonstrou-se que, após a análise dos vazamentos de provas e da postura atuante na busca de provas do juiz Sérgio Moro, o expresidente, a quem o julgador fez tudo que tinha em seu poder para manter preso, foi solto por maioria em julgamento pelo Supremo Tribunal Federal.

Recorda-se, mais uma vez, que o presente artigo teve o intuito de analisar os atores do processo penal e utilizou-se, para tanto, do caso de maior repercussão dos últimos tempos que foi a Operação Lava-Jato com a prisão do ex-presidente José Inácio Lula da Silva. Entretanto, não se afirma aqui nenhuma posição político partidária, mas tão somente a análise dos operadores jurídicos.

A atuação prática dos sujeitos processuais não é ilimitada, importante que isso fique evidenciado no contexto social. A atividade dos sujeitos processuais nos foros e tribunais deverá primar pelos princípios do contraditório, ampla defesa, igualdade entre as partes, 
pautando-se sempre pelas regras do jogo democrático, afastando-se e refutando por completo qualquer prática autoritária. Nesse contexto, reputa-se como primordial que se repense e observe o desempenho dos Juízes Criminais e sua relação no âmbito do processo, pois quanto mais contido for esse magistrado e mais se reconhecer como um sujeito vulnerável às práticas autoritárias, ainda facultadas pela legislação processual, maior serão as chances de se concretizar o seu papel principal, de juiz garantidor de direitos e garantias, limitador de todo o anseio punitivo e comprometido com o projeto democrático.

O Brasil necessita amadurecer seu regime democrático e suas instituições. Os agentes públicos pátrios precisam adequar-se a um quadro em que suas atuações se limitam pelo cumprimento do texto constitucional e da observância das garantias individuais. Os ideais propostos pela teoria garantista de Ferrajoli mostram-se, pois, atuais e necessários para se consolidar o processo democrático pátrio.

\section{BIBLIOGRAFIA}

ADVOGADOS. Carta Aberta. Disponível em: <https://www.conjur.com.br/dl/advogadosafastamento-moro-ministerio.pdf > Acesso em: 08/08/19

BRASIL. Constituição (1988). Constituição da República Federativa do Brasil de 1988. Disponível em: <http://www.planalto.gov.br/ccivil_03/constituicao/ConstituicaoCompilado.htm>. Acesso em 17 de outubro de 2015.

BRASIL. Decreto-Lei no 2.848, de 7 de Dezembro de 1940. Código Penal. Disponível em: <http://www.planalto.gov.br/ccivil_03/decreto-lei/Del2848.htm>. Acesso em 17 de outubro de 2015.

BRASIL. Supremo Tribunal Federal. Habeas Corpus 95.518. Relator: Ministro Gilmar Mendes. Disponível em: $<$ http://redir.stf.jus.br/paginadorpub/paginador.jsp?docTP=TP\&docID=5463892> Acesso em: 08/09/19.

CÁRCOVA, Carlos María. Qué Hacen los Jueces Cuando Juzgan? Revista Da Faculdade de Direito da UFPR, v. 35, 2001. p. 17

CARNELUTTI, Francesco. As misérias do processo penal. 5. ed. Campinas: Bookseller, 2004.

CARVAlHO, Amilton Bueno de. A lei. o juiz. O justo. AJURIS: Revista da Ajuris, Porto Alegre, Ajuris v.14, n.39, MAR/1987, p. 132-152. 
CARVALHO, Amilton Bueno de. Eles, os juízes criminais, vistos por nós, os juízes criminais. Rio de Janeiro: Lumen Juris, 2014.

CARVALHO, Amilton Bueno de. AJURIS: Revista da Ajuris, Porto Alegre, Ajuris v.24, n.70, JUL/1997, p. 345--373.

COUTINHO, Jacinto Nelson de Miranda. O papel do novo juiz no processo penal. Disponível em:/ <https://emporiododireito.com.br/leitura/o-papel-do-novo-juiz-no-processopenal> Acesso em: 08/08/19.

CARVALHO, Salo de. O papel dos atores do sistema penal na era do punitivismo: (o exemplo privilegiado da aplicação da pena). Rio de Janeiro: Lumen Juris, 2010.

FERRAJOLI, Luigi. Derecho y razón - Teoria del garantismo penal. Editorial Trotta. 1997, $2^{\mathrm{a}} \mathrm{Ed}$

FERRAJOLI, Luigi. Derechos y garantias: La ley del más débil. Madrid: Ed. TROTTA, $2001,2^{\mathrm{a}}$ ed.

GIACOMOLLI, Nereu José. O devido processo penal: abordagem conforme a Constituição Federal e o Pacto de São José da Costa Rica. São Paulo: Atlas, 2014.

GLOECKNER, Ricardo Jacobsen. Nulidades no Processo Penal. $3^{\text {a }}$ ed. São Paulo: Saraiva, 2018.

GREENWALD, Glenn.; REED, Betsy; DEMORI, Leandro. COMO E POR QUE O INTERCEPT ESTÁ PUBLICANDO CHATS PRIVADOS SOBRE A LAVA JATO E SERGIO MORO. Disponível em: https://theintercept.com/2019/06/09/editorial-chatstelegram-lava-jato-moro/ Acesso em 09/08/19.

LOPES JR, Aury. Direito processual penal. 14. ed. - São Paulo: Saraiva, 2017.

MAYA, André Machado. Imparcialidade e processo penal - da prevenção da competência ao juiz de garantias. $2^{a}$ ed. rev. e ampl. São Paulo: Atlas, 2014.

MENDES, Gilmar Ferreira; BRANCO, Paulo Gustavo Gonet. Curso de direito constitucional. 9a ${ }^{a}$ ed. São Paulo: Saraiva, 2014.

OLIVEIRA, Eugênio Pacelli de; FISCHER, Douglas. Comentários ao código de processo penal: e sua jurisprudência. 3. ed. Rio de Janeiro: Lumen Juris, 2011.

POLÍCIA FEDERAL. Disponível em: <http://www.pf.gov.br/imprensa/lava-jato> Acesso em: 09/08/19.

SOUZA, José Francisco Fischinger Moura de. Juiz criminal: do garantidor ao inquisidor? A distinção entre normatividade e efetividade em uma abordagem dos papéis do juiz no processo penal brasileiro. 2004. 406 f. Dissertação (Mestrado) - Pontifícia Universidade 
Católica do Rio Grande do Sul, Programa de Pós-Graduação em Ciências Criminais, Porto Alegre, 2004.

TOLEDO, Cláudia. Direito Adquirido e Estado Democrático de Direito. São Paulo: ed. Landy, 2003 